\title{
HOW TO ASSESS THE SIGNIFICANCE OF ENVIRONMENTAL IMPACTS
}

\author{
PAULO ROBERTO A. TAGLIANI \& TATIANA WALTER \\ Coastal Management Centre, Institute of Oceanography, Federal University of Rio Grande, Brazil
}

\begin{abstract}
In the context of the Environmental Impact Studies, the determination of the significance of the impacts is a fragile aspect that has been the subject of discussion and criticism in the international scientific community. There are no objective criteria for such determination, resulting in very subjective evaluations, generally determined by the analysts' experience and influenced by their professional profile. The commonly employed methods are derived from normative valuations using certain rating scales, which are used in the same way for quite different ecological, economic and social processes. Then, once a ranking of impacts significance values is established, the subjectivity of the process is hidden under a seemingly objective number. The proposed method establishes a simple routine of integrated analysis considering a set of characteristics of environmental impacts, including persistence, reversibility spatial amplitude, synergy magnitude, and cumulative effects. Although this method does not eliminate the subjectivity of the process, it makes explicit the criteria used for assessing the significance of impacts providing greater transparency to the process, contributing to a broader understanding of the profile of the impacts of the project.

Keywords: impact significance assessment, Environmental Impact Assessment, Environmental Impact Study, social participation.
\end{abstract}

\section{INTRODUCTION}

Environmental Impact Assessment (EIA) can be characterized as a preventive environmental policy and management process. It has been adopted worldwide to consider the environmental effects of projects, plans and programs in a comprehensive and systematic manner (Pölönen et al. [1]). As one of the pillars in the EIA, the Environmental Impact Study (EIS) is a main analysis tool which relies on concepts and methods that are still evolving. In EIS context, one of its key concept is the Impact Significance, whose assessment is a critical step in the EIA and this has been the subject of discussion and criticism in the international scientific community (Ehrlich and Ross [2]). Wood and Becker (in Lawrence, [3]) emphasized that such assessment remains one of the most complex and least understood of EIA activities.

The existent methods for Impact Significance Assessment (ISA) tend to be highly variable and there are no objective criteria for such determination, resulting in very subjective evaluations, generally determined by the analysts' experience and influenced by their professional profile and personal values. Several authors have discussed this issue since the 1980s, including Beanlands and Duinker [4], Canter and Canty [5], Erickson [6], Marusich [7], Lawrence [3], [8], [9] and Toro et al. [10], among others. The personal value system is influenced by several aspects of the individual, including culture, social condition, geographical situation and the historical moment. According to Beattie (in Wilkins [11]) the personal values system will affect the impact assessment, the delimitation of the scope, the assumed assumptions in the methodology to be adopted and may vary with the social groups involved. Lawrence [8], grouped the set of existing approaches to assess the significance of impacts in Technical, Collaborative, Argumentative and Composite. The commonly employed methods derived from normative valuations use certain rating scales, which are used in the same way for quite different ecological, economic and social processes. Then, 
once a ranking of impacts significance values is established, the subjectivity of the process keeps hidden under a seemingly objective number or scale.

In the scientific literature there is a consensus about the inherent subjectivity of the EIS, (Loomis and Dziedzi [12]). According to Toro et al. [10], qualitative methods are used because they are versatile and easy to apply, but it is important to make clear the qualitative criteria employed, and to make explicit the data used to get the results. Ehrlich and Ross [2] pointed out that subjective does not mean arbitrary - those using subjective informed judgments to make significance determinations still must rely on the evidence that has been brought forth by the participants of the EIA and must use cogent reasoning.

In discussing the effectiveness of Environmental Impact Assessments, Rozema and Bond [13] agreed with Wilkins [11], considering that the subjectivity inherent in the process is not a fragility per se, and that the effectiveness of Impact Assessment instruments should be assessed as a measure of their capacity to accommodate different discourses of civil society that were mobilized in the context of policy decisions in the development of the project.

A second well-established limit in scientific literature is the low participation of society in EIA (Morgan [14]). That is, if there is a subjectivity in the definition of ISA and if it is social value dependent, the decision-making process involving the EIS should be expanded, so that society - especially social groups directly affected by implementation of a given economic activity - would define its viability. In this sense, there is a need to combine a method of assessing significance to the process of social participation. Consequently, the method itself must present transparent criteria in order to allow the construction of scales of values and attributes by the different social actors involved in the environmental impact assessment. Harding (in Ehrlich and Ross [2]) emphasized that inadequate consideration of values often underlies apparent disagreements over fact in the environmental decisionmaking process.

In this sense, the objective of this article is the proposition of a method of analysis of significance that subsidizes a greater process of social participation in the EIA, being exemplified from the Brazilian reality. The proposal methodology does not aim to eliminate the subjectivity, but clarify the criteria used systematically to define the impacts significance, contributing to a broader understanding of the profile of the impacts of projects.

\section{ENVIRONMENTAL LICENSING IN BRAZIL: CHARACTERISTICS OF SOCIAL PARTICIPATION UNRELATED TO A SIGNIFICANCE ANALYSIS}

In Brazil, the EIA was established in 1981 as one of the instruments of the National Environmental Policy - PNMA (Presidency of the Republic Civil House [15]), still in a political context of military dictatorship. Its proposal came about because of demands from international agencies that financed public infrastructure and not from popular pressure, since social demonstrations were heavily suppressed by that political system.

Its institutionalization is linked to environmental licensing, an instrument also foreseen in PNMA. Thus, in Brazil the EIA constitutes a prognosis of impacts that guides a technicaladministrative process of responsibility of one of the environmental agencies that compose the National System of Environment. That is, depending on the magnitude of the impacts and the location where the activity will be implemented, the responsibility for environmental licensing may be federal, state or municipal.

In practice, EIA and environmental licensing are project oriented, although there are some initiatives in the EIA proposal for plans and programs, called Strategic Environmental Assessment, they are still incipient and lack normatization (Sánchez [16], Margato and Sánchez [17]). 
According to Sánchez [18] environmental licensing is the procedural EIA, that is, its orientation is the prognosis of impacts and it uses a series of steps to decide the environmental viability of a given economic activity. The EIS is the technical study that establishes the central elements of decision-making. The analysis of significance is an instrument that is part of the Environmental Study and that articulates the characteristics of the enterprise and the environment.

In addition to the EIS, the environmental agency responsible for licensing conducts technical surveys, directs the study to the manifestation of other related organs and, in some cases, conducts a public hearing. After the decision on the environmental feasibility of the enterprise, it is the responsibility of the environmental agency to monitor the implementation of the constraints required in the environmental license. Table 1 summarizes the stages of environmental licensing in Brazil.

In this country, the debate about social participation, anchored to the process of redemocratization, did not reverberate in a greater social participation in environmental licensing. The 1980s guidelines were maintained (CONAMA [19], [20]), they established a limited participation of the population in general, including the population affected by the enterprise. This participation is restricted to presenting the EIS and clarifying doubts and it is only required when civil society, the Public Ministry or more than 50 citizens formally demand its realization.

Thus, although the EIA is the most consolidated instrument of Brazilian environmental policy and its importance is widely recognized, one of the most recurrent criticisms is the lack of social participation (Faria and Silva [21], Silva et al. [22] and Zhouri [23]), especially from a radicalized perspective of democracy.

Rozema and Bond [13], Morgan [14], Arce-Gomez et al. [24] among others, emphasized that social participation was a necessary element in the effectiveness of EIA. The main criticisms, according to Morgan [14], can be applied to the Brazilian case (Duarte et al. [25]): i) Difficulty in accessing licensing information; ii) Normative restrictions; iii) Lack of legal advice/assistance; iv) distrust of industry; v) NIMBY Syndrome "Not in my backyard"; vi) Inability to influence the decision-making process (participation restricted to information and consultation); and vii) Absence of effective mechanisms to promote participation.

However, Uema [26] and Zhouri [23] pointed out that, in Brazil, social participation in licensing is still hampered by broad social inequality, whose cognitive dimension results in real limitations to the affected population in public hearings. For both authors, low schooling, the formal rite of public hearings, the excessive technical discourse detached from a clear construction around how the scope of the study was defined and how the impacts were measured hinder social participation. Silva et al. [22] pointed out, through a case study, how the public hearing serves the promotion of the enterprise and not the debate about its environmental viability.

\section{BASIC CONCEPTS TO THE IMPACT SIGNIFICANCE ASSESSMENT}

A clear definition of the concepts and methods used in determining significance provides transparency and trust in the analysis, allowing the affected communities a greater understanding of the criteria adopted and discussion of the results on a common basis. Typically the ISA include impact characteristics such as magnitude, duration, frequency, moment, likelihood, reversibility, probability of occurrence, mitigation, accumulation, and the compliance with regulations and/or legal standards (Ehrlich and Ross [2], Toro et al. [10]). 
Table 1: The ISA in a context of EIA process in Brazil.

\begin{tabular}{|c|c|c|c|}
\hline Phase & Social actor & Component & Description \\
\hline Screening & Environmental agency & $\begin{array}{l}\text { Sometimes it requires } \\
\text { consultation with other } \\
\text { agencies related to } \\
\text { indigenous, historical } \\
\text { and cultural issues }\end{array}$ & $\begin{array}{l}\text { Assessment based on } \\
\text { legislation and project } \\
\text { characteristics (type and } \\
\text { size) whether the project } \\
\text { requires a single license or } \\
\text { a full environmental impact } \\
\text { study. }\end{array}$ \\
\hline Scoping & Environmental agency & & $\begin{array}{l}\text { Definition of the Terms of } \\
\text { Reference to the EIS }\end{array}$ \\
\hline \multirow[t]{5}{*}{ EIS } & \multirow[t]{5}{*}{ Consulting firm } & Project analysis & $\begin{array}{l}\text { Description of the } \\
\text { project/actions and } \\
\text { technological alternatives }\end{array}$ \\
\hline & & $\begin{array}{l}\text { Analysis of locational } \\
\text { alternatives }\end{array}$ & $\begin{array}{l}\text { Spatial analysis using GIS } \\
\text { tools }\end{array}$ \\
\hline & & $\begin{array}{l}\text { Environmental/socioec } \\
\text { onomic diagnosis }\end{array}$ & $\begin{array}{l}\text { Field and bibliographical } \\
\text { data collection of } \\
\text { socioeconomic, ecological } \\
\text { and biophysical and legal } \\
\text { aspects }\end{array}$ \\
\hline & & Impact analysis & $\begin{array}{l}\text { Identification of } \\
\text { environmental aspects and } \\
\text { impacts in the construction } \\
\text { and operation phases. } \\
\text { Impact Significance } \\
\text { Assessment }\end{array}$ \\
\hline & & $\begin{array}{l}\text { Environmental } \\
\text { programs }\end{array}$ & $\begin{array}{l}\text { Definition of a set of } \\
\text { programmatic actions to } \\
\text { eliminate, mitigate, control, } \\
\text { compensate and monitor } \\
\text { impacts }\end{array}$ \\
\hline $\begin{array}{l}\text { Public } \\
\text { hearing }\end{array}$ & $\begin{array}{l}\text { Environmental agency, } \\
\text { consulting firm, } \\
\text { entrepreneur, public }\end{array}$ & $\begin{array}{l}\text { Public call } \\
\text { Public hearing }\end{array}$ & $\begin{array}{l}\text { Consultation with the } \\
\text { community to support } \\
\text { decision making. }\end{array}$ \\
\hline Licensing & Environmental agency & $\begin{array}{l}\text { Technical Analysis of } \\
\text { the EIS x public } \\
\text { hearing } \\
\text { Technical visit }\end{array}$ & $\begin{array}{l}\text { The license is usually } \\
\text { granted in three stages by } \\
\text { analyzing the fulfillment of } \\
\text { conditions: } \\
\text { - Previous license } \\
\text { - Installation license } \\
\text { - Operation license } \\
\end{array}$ \\
\hline $\begin{array}{l}\text { Follow } \\
\text { up }\end{array}$ & $\begin{array}{l}\text { Environmental agency } \\
\text { Consulting firm }\end{array}$ & $\begin{array}{l}\text { Analysis of monitoring } \\
\text { data }\end{array}$ & $\begin{array}{l}\text { Depending on the } \\
\text { monitoring results the } \\
\text { environmental license may } \\
\text { not be renewed or } \\
\text { suspended }\end{array}$ \\
\hline
\end{tabular}


Toro et al. [10], pointed out the ultimate goal in the ISA is to reduce the role of the evaluator, recommending to use simple aggregation operators, even if they are less precise than more sophisticated choices.

Among other aspects, Lawrence [8] criticized ISA addressing only negative and biophysical impacts and recommended as generic criteria to determine the threshold of Impact Significance the following: magnitude, reversibility, positive or negative, frequency, likelihood, spatial extent, uncertainty, complexity. Nevertheless, broadening the scope of impact significance determination is useful to establish the context and to keep the goal of sustainability, some of these characteristics do not contribute to determine the impact significance. The information if an impact is positive or negative does not contribute to elucidating its significance. This does not mean, however, that they should not be considered. It is assumed that they should be identified and analyzed in the same way as the negative impacts, to proceed to cost-benefit analysis of the project. Also, as likelihood and frequency: such criteria should be applied in the context of risk when determining significance. For worst-case-type scenarios (meaning low-probability high-consequence events), even an unlikely impact may be unacceptable if it is severe enough, as pointed out by Ehrlich and Ross [2].

The proposal method evaluates the significance based on integrated analyses of the following impact characteristics: Persistence, Reversibility Spatial Amplitude, Synergy Magnitude, and Cumulative effects. In order to establish a common theoretical base to apply in the ISA we propose the following definitions of these concepts: Regarding persistence, it is assumed that impacts can be Permanent or Temporary. Permanent impacts should be understood as those that remain as long as the action persists, for example, noise in an industrial plant. Temporary impacts are those that cease in the short-medium term even with the permanence of the causative action, for example the change in marine sandy habitat due to excavation for the installation of a marine cable or duct. Considering the degree of reversibility, impacts considered irreversible are those that, once triggered, the environment has a low probability of returning to its original state, even regardless of whether the action continues or not, for example, the removal of a habitat to install a building. As to the spatial amplitude, restricted impacts are those in which spatial scope is limited to the space of the project and/or its immediate vicinity, while a diffuse impact extends beyond these limits. As to the synergy, a synergistic impact is that one whose effect is multiplied in the presence of certain environmental conditions or other pre-existing impacts, such as the disposal of a thermal effluent in a tropical estuarine embayment. As to the criteria of Magnitude, the concept is used in the sense of intensity of impact and can be measured in the most varied scales according to their nature, such as decibels, concentration in $\mathrm{g} / \mathrm{m}^{2}$, flow rates in $\mathrm{m}^{3} / \mathrm{s}$, Celsius degree, etc. In this case, the legal standards and regulations can be very useful, but is not enough as single criterion. As Ehrlich and Ross [2] emphasized, an impact may meet government determined objectives, regulations and standards, and still be significant for other reasons.

Finally, Cumulative Impacts could be understood as those that result from the incremental effect of an action when added to others past, present or reasonably predictable in the future. Such impacts are difficult to predict and there is little consensus on how evaluation can be done, so they are generally poorly covered or absent from the EIA (Pavlickova and Vyskupova [27]).

It is noteworthy that several authors (Ehrlich and Ross [2], Rozema and Bond [13], ArceGomez et al. [24]), consider Impact Significance in a context of Social Acceptance, but it is convenient to establish this difference of concepts for several reasons: (1) Due to the hierarchical scale of the perception, an impact can have a level of acceptance at a local level 
distinct from the regional or national level. For example, mining projects may have a national strategic interest but socio-environmental impacts on a local scale may render the project unacceptable to the affected community that does not depend on the jobs generated by the activity and which will have their livelihoods profoundly altered; (2) Due to the intergenerational pact: Social acceptance is dependent on the environmental, social, political and economic context and therefore variable with time. A thermoelectric plant that consumes large volumes of water may be acceptable in a water-abundant condition and job shortage, but this perception may change in the future of water scarcity and employment alternatives; (3) Due to international agreements and legal basis: Impacts on a species threatened with extinction, or cultural/natural heritage, can hurt international agreements and national laws, but a local community lacking jobs and income may not care about the extinction of a species, or cultural/natural heritage that they do not depend on directly. Social acceptance does not necessarily mean local acceptance. The legal basis of a country is the highest level of social agreement and the federative pact must be respected. So, the acceptance of an impact is a social and political decision that must be taken from the impact assessment, and this should be done based on a combination of top-down and bottom-up approaches, based on societal values.

The proposed method follows a protocol, where the ordered sequence of analysis of several possibilities of combinations of impact characteristics (ecological, socioeconomic and bio-physical) will lead to determination of different significance level. (Fig. 1). The advantage of such methodology is that it needs an explicit analysis that leads to the evaluation of each impact characteristic.

In this conception, social participation is facilitated, in particular, if the participants have the opportunity to know previously the criteria to be applied in the ISA and contribute with the environmental agency in such evaluation according their community values. The role of the analyst should be to apply specific methods and techniques for analyzing biotic, abiotic

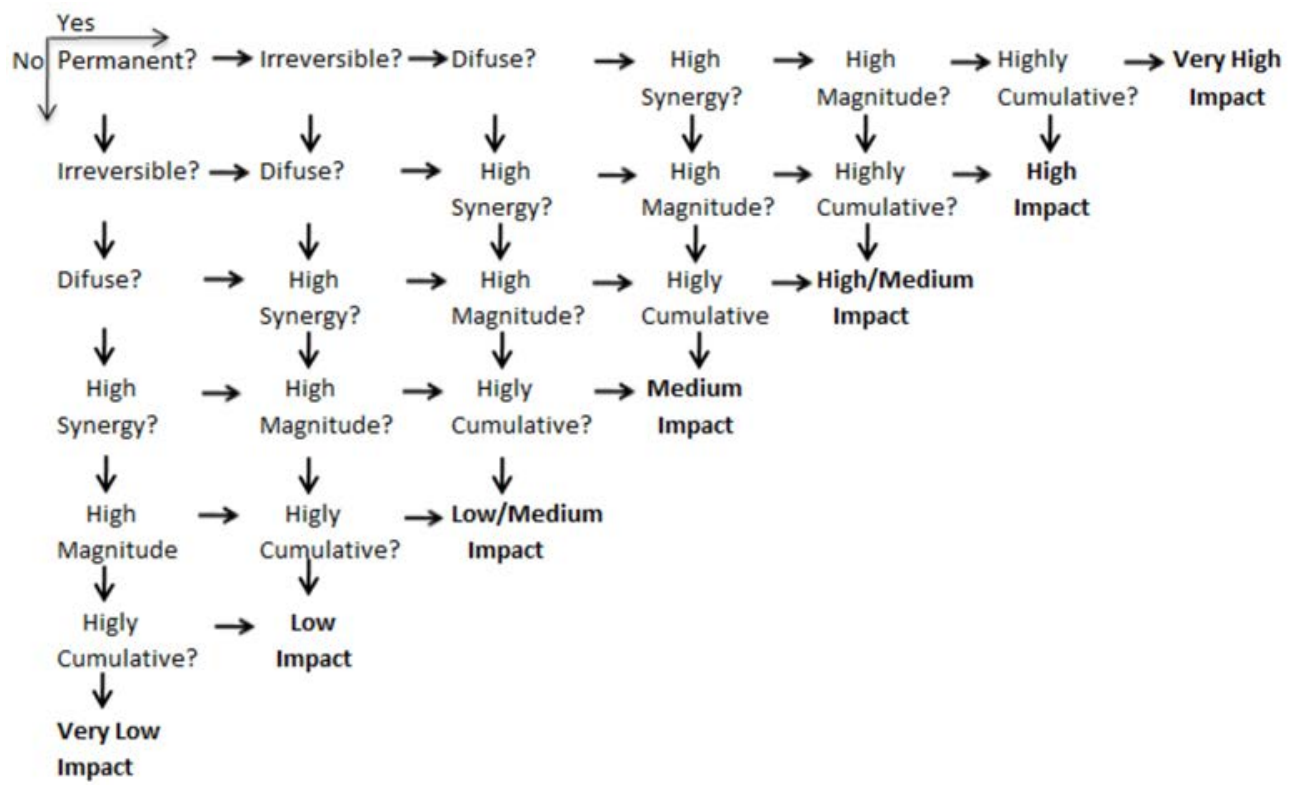

Figure 1: Protocol for impact significance assessment. 
and socioeconomic data (including local social values) and government plans and programs to justify the framing of impacts according to the pre-established criteria.

However, in the Brazilian environmental licensing, it is also necessary to involve society from the definition of the scope of the study, so that they can list the questions they wish to be investigated, and later, decide on the environmental viability of the activity. Participation in the early phase of planning and a communicative planning style have made it possible to strengthen the trust between stakeholders, enabling consensus in conflicts, as pointed out by Pölönen et al. [1].

\section{CONCLUSION}

One of its key functions of the Environmental Impact Assessment is to provide a forum for public participation broadening the information base for decision making and, ideally, leading to sustainable planning, policy and development choices (Pölönen et al. [1]).

The Significance Impact Assessment is the main pillar that underpins the decision-making processes, and there are technical approaches still without clear criteria underlying the evaluation.

There are many published guidelines describing criteria for impact evaluation, and there is a recognition that values play a role in significance determinations. However, there is little straightforward guidance available to EIA decision-makers on how exactly to apply values to impact predictions to reach significance determinations (Ehrlich and Ross, [2]). Cashmore et al. [28] concluded that, at least within the contemporary research context, learning derived from analyzing the meaning and implications of multiple interpretations of effectiveness represents the most constructive strategy for advancing impact assessment and policy integration theory. According to Lawrence [3], [8], [9] the determination of the impact significance should be clearer, less biased and distorted, broadening (in terms of criteria), focused, explicit, logical, traceable, adequate, consistent, inclusive, collaborative, efficient, adaptive more effectively linked to decision-making and EIA practice.

Although the proposed method does not eliminate the subjectivity of the determination, it makes explicit the criteria used for assessing the significance of impacts providing greater transparency to the process, contributing to a broader understanding of the profile of the impacts of the project. Nevertheless the clear definition of each concept and the criteria adopted to its delimitation is important to get consistence. Before representing a return to positivist approaches, the method provides a basis for a participatory assessment of the significance of the impact, making it possible to incorporate the perception of the affected communities.

\section{REFERENCES}

[1] Pölönen, I., Hokkanen, P. \& Jalava, K., The effectiveness of the Finnish EIA system: What works, what doesn't, and what could be improved? Environmental Impact Assessment Review, 31, pp. 120-128, 2011.

[2] Ehrlich, A. \& Ross, W., The significance spectrum and EIA significance determinations. Impact Assessment and Project Appraisal, 33(2), pp. 87-97, 2015.

[3] Lawrence, D.P., Impact significance determination: Designing and approach. Environmental Impact Assessment Review, 27, pp. 730-754, 2007.

[4] Beanlands, G.E. \& Duinker, P.N., An Ecological Framework for Environmental Impact Assessment in Canada, Federal Environmental Assessment Review Office and Institute for Resource and Environmental Studies: Hull, Quebec and Halifax, Nova Scotia, 1983. 
[5] Canter, L.W. \& Canty, G.A., Impact significance determination: Basic considerations and a sequenced approach. Environmental Impact Assessment, 13, pp. 275-297, 1993.

[6] Erickson, P.A., A Practical Guide to Environmental Impact Assessment, Academic Press: San Diego, CA, 1994.

[7] Marusich, S., The Application of Fuzzy Logic Analysis to Assessing the Significance of Environmental Impacts: Case Studies from Mexico and Canada, Canadian Environmental Assessment Agency, 2001.

[8] Lawrence, D.P., Impact significance determination: Pushing the boundaries. Environmental Impact Assessment Review, 27, pp. 770-788, 2007.

[9] Lawrence, D.P., Impact significance determination: Back to basics. Environmental Impact Assessment Review, 27, pp. 755-769, 2007.

[10] Toro, J.A., Requena, I.B., Duarte, O.C. \& Zamorano, M.D.A., Qualitative method proposal to improve environmental impact assessment. Environmental Impact Assessment Review, 43, pp. 9-20, 2013.

[11] Wilkins, H., The need for subjectivity in EIA: Discourse as a tool for sustainable development. Environmental Impact Assessment Review, 23, pp. 401-414, 2003.

[12] Loomis, J.J. \& Dziedzi, M., Evaluating EIA systems' effectiveness: A state of the art. Environmental Impact Assessment Review, 68, pp. 29-37, 2018.

[13] Rozema, J.G. \& Bond, A.J., Framing effectiveness in impact assessment: Discourse accommodation in controversial infrastructure development. Environmental Impact Assessment Review, 50, pp. 66-73, 2015.

[14] Morgan, R.K., Environmental impact assessment: The state of the art. Impact Assessment and Project Appraisal, 30(1), pp. 5-14, 2012.

[15] Presidency of the Republic Civil House, Sub-Office for Legal Affairs, Law No. 6.938 of 31 August 1981.

[16] Sánchez, L.E., Porque não avança a Avaliação Ambiental Estratégica no Brasil? Estudos Avançados, 31(89), pp. 167-183, 2017.

[17] Margato, V. \& Sánchez, L.E.J., Quality and outcomes: A critical review of Strategic Environmental Assessment in Brazil. Env. Assmt. Pol. Mgmt., 16, 2014.

[18] Sánchez, L.E., Avaliação de Impacto Ambiental. Conceitos e Métodos, São Paulo, 2006.

[19] CONAMA, Resolução No. 1/1986 Publicada no DOU of 17 February 1986, Seção 1, pp. 2548-2549, 1986.

[20] CONAMA, Resolução No. 009/1987, Data da legislação: 03/12/1987 Publicação DOU of 5 July 1990, p. 12945, 1990.

[21] Faria, G.C. \& Silva, F.M., Participação pública no processo de avaliação de impacto ambiental no estado do Espírito Santo. Desenvolv. Meio Ambiente, Edição Especial: Avaliação de Impacto Ambiental, 43, pp. 139-151, 2017.

[22] Silva, R.H., Walter, T. \& Soto, W.H.G., A audiência pública no licenciamento ambiental: instância de democratização do processo ou de promoção do empreendimento? Diversidade Sociológica - Facetas da Pesquisa em Sociologia, eds E. Garcia da Costa, B. Anhaia, C. Schuck, C. Anello \& Y.P. Cerpa Aranda, 1st ed., vol. II, pp. 171-190, 2016.

[23] Zhouri, A., Justiça Ambiental, Diversidade Cultural e Accountability: Desafios para Governança Ambiental. Revista Brasileira de Ciências Sociais, 23(68), pp. 97-107, 2008.

[24] Arce-Gomez, A., Donavan, J.D. \& Bedggood, R.E., Social impact assessments: Developing a consolidated conceptual framework. Environmental Impact Assessment Review, 50, pp. 85-94, 2015. 
[25] Duarte, C.G., Dibo, A.P.A. \& Sánchez, L.E., O que diz a pesquisa acadêmica sobre avaliação de impacto e licenciamento no Brasil? Ambiente \& Sociedade, $\mathbf{X X}(1), \mathrm{pp}$. 245-278, 2017.

[26] Uema, E.E., Controle Social, Saber Perito e Participação. Educação Ambiental no contexto de medidas mitigadoras e compensatórias de impactos ambientais: a perspectiva do licenciamento, ed. C.F.B. Instituto do Meio Ambiente - IMA: Loureiro, Salvador/BA, pp. 49-80, 2009.

[27] Pavlickova, K. \& Vyskupova, M., A method proposal for cumulative environmental impact assessment based on the landscape vulnerability evaluation. Environmental Impact Assessment Review, 50, pp. 74-84, 2015.

[28] Cashmore, M., Richardson, T., Hilding-Ryedvik, T. \& Emmelin, L., Evaluating the effectiveness of impact assessment instruments: Theorizing the nature and implications of their political constitution. Environmental Impact Assessment Review, 30, pp. 371-379, 2010. 